\title{
Use of a Metal Detector to Locate Permanent Plots
}

\author{
JEFFREY WEIGEL AND CARLTON M. BRITTON
}

Marking permanent sampling plots for easy relocation without affecting test results can be difficult, particularly in grazing studies. Aboveground plot markers may change animal movements and behavior, be pulled up or knocked over by livestock, alter treatment effects, or attract unwanted human attention. Protruding markers can also damage vehicles or injure livestock and researchers.

In a study evaluating impacts of cattle trampling on grass seedling emergence, a series of plots were established. It was imperative that plot markers not alter cattle behavior, making belowground markers a necessity. Repeated sampling during and between grazing periods required that plots be easily relocated.

Each plot was marked at 2 corners with $35-\mathrm{cm}$ lengths of $1.0-\mathrm{cm}$ diameter steel reinforcing rod inserted vertically into the soil, with tops flush with or slightly below the surface. Approximate plot locations were mapped from relatively permanent reference landmarks, such as exclosure fences used in the study. Fence corners, bench marks, or other reasonably permanent reference landmarks could also be used. Soft aluminum plant tags recording direction and distance to each plot were installed at reference points.

Prior to each sampling period, a ferromagnetic metal detector (Schonstedt Model GA-52B) was used to relocate plots. Differences in magnetic fields caused by plot markers are translated to changes in frequency of an audible tone emitted by the detector. Approximate plot locations were found using reference point directions and pacing. The detector was then used. Using a sweeping motion, large areas were quickly searched, requiring only approximate plot locations from pacing. Once located, plots were temporarily marked with wire flags. It was possible for one person to relocate and mark $32,0.25-\mathrm{m}^{2}$ plots spread over 2 ha in about 1 $\mathrm{hr}$ using this system. To relocate similarly marked plots without the metal detector would require extensive, precise measurement from reference points and would be time-prohibitive.

Iron markers (1.25-cm diameter carbon steel pipe) commonly used by surveyors are more easily detected than the $1.0-\mathrm{cm}$ diameter reinforcing rod but cost 3 times more $(\$ 1.50 / \mathrm{m}$ vs. $\$ 0.35 / \mathrm{m})$. A ferromagnetic detector (cost: $\$ 550.00$ ) was selected because of its sensitivity to steel and iron and lack of response to nonferrous

\footnotetext{
The authors are graduate research assistant and associate professor, Department of Range and Wildlife Management, Texas Tech University, Lubbock, Texas 79409.

This article is contribution No. T-9-430 of the College of Agricultural Sciences, Texas Tech University.

Manuscript accepted 18 March 1986.
}

materials such as water, aluminum, brass, and copper. Plot relocation can be improved by installing plastic-sealed magnetic caps (\$1.75 each) atop one marker per plot. The caps greatly enhance detectability in dense vegetation where it is difficult to sweep the detector arm.

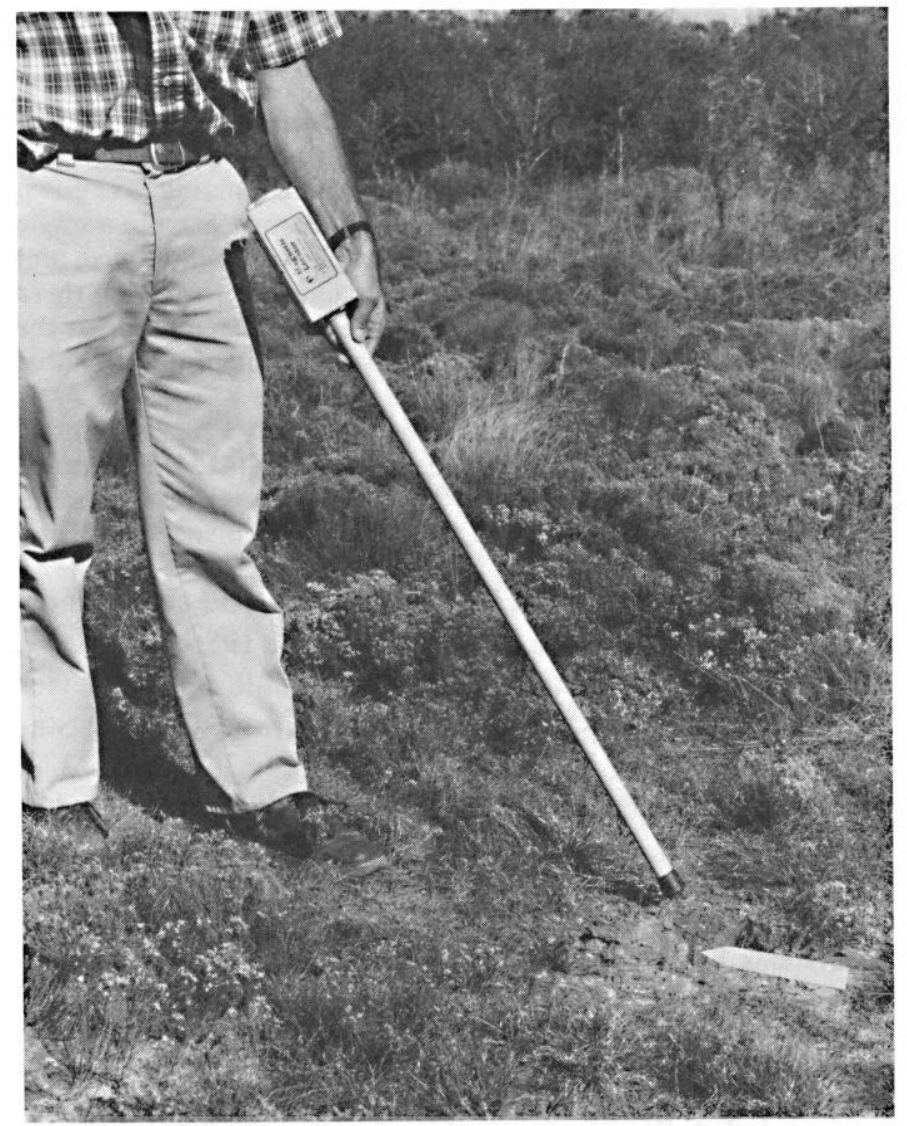

Fig. 1. Metal detector locating steel stake (arrow) which would be below the soil surface. 